\title{
Control over noxious events and choice
}

\author{
BRUCE ABBOTT and PIETRO BADIA \\ Bowling Green State University, Bowling Green, Ohio 43403
}

\begin{abstract}
Three experiments are reported assessing whether rats prefer controllable over uncontrollable aversive shock. In Experiment 1, subjects chose between escapable and inescapable shock while relative shock duration varied parametrically. In Experiment 2, subjects again chose between escapable and inescapable shock, but duration was held constant and equal. The final experiment gave subjects a choice between avoidable and unavoidable shock under several signaling conditions. Choice behavior proved sensitive to relative shock duration and to predictability of shock but not to controllability of shock.
\end{abstract}

Controllability and predictability are closely related dimensions. When an event is controllable, it is contingent upon the occurrence of a response. When an event is predictable, it is contingent upon the occurrence of a stimulus. Over the past several years, research in our laboratory has focused on the effects of predictability on choice behavior. This has involved comparisons between predictable and unpredictable controllable events (e.g., Badia \& Culbertson, 1972; Badia, Culbertson, \& Lewis, 1971) and between predictable and unpredictable uncontrollable events (e.g., Badia \& Culbertson, 1972; Badia, Harsh, Coker, \& Abbott, 1976; Fisher \& Badia, 1975). This work has consistently demonstrated a strong preference for predictable over unpredictable aversive events that is independent of the presence or absence of control. In light of the conceptual similarity between controllability and predictability, it may be that a similar preference exists for controllable over uncontrollable aversive events.

Several findings indirectly support this prediction. These findings suggest that controllable shock conditions are less aversive than uncontrollable shock conditions. For example, stimuli paired with escapable shock produce less response suppression than do stimuli paired with inescapable shock (Desiderato \& Newman, 1971; Imada \& Soga, 1971; Mowrer \& Viek, 1948; Osborne, Mattingly, Redmon, \& Osborne, 1975). Further, less ulceration is produced by escapable shock (Moot, Cebula, \& Crabtree, 1970) and by avoidable-escapable shock (Weiss, 1968, Experiment $2,1971 \mathrm{a}, 1971 \mathrm{~b}$ ) than by shock that is unavoidable and inescapable. Similarly, controllable shock

Experiment 1 of this report was based on a thesis submitted by the first author under the direction of the second to the Graduate School of Bowling Green State University in partial fulfillment of the requirements for the MA degree. The research was supported by Grant BG-33725 from the National Science Foundation. Reprints may be obtained from Pietro Badia, Department of Psychology, Bowling Green State University, Bowling Green, Ohio 43403. produces less weight loss and faster weight gain (Weiss, 1968, 1971a, 1971c) and results in less depletion of whole-brain norepinephrine (Weiss, Stone, \& Harrell, 1970).

If, as these data suggest, controllability reduces the aversiveness of noxious situations, then subjects should prefer those conditions where control over shock is available over those where such control is absent. However, a direct test of this prediction by Schuster and Rachlin (1968) failed to obtain such a preference. ${ }^{1}$ They gave pigeons in a concurrent-chains procedure a choice between a terminal link containing response-dependent shock and one containing response-independent shock. Terminal-link responding was more suppressed in the response-dependent condition, indicating that the punishment contingency was effective. However, choice was not affected by the presence or absence of control but depended only upon the relative frequency of shock.

Assuming that controllable shock would normally be an important determinant of choice, what could explain these results? A possible argument relates to shock intensity. Since responding was maintained by an appetitive schedule, only relatively mild shock could be delivered without suppressing the frequency of responding to zero. From this low level of noxiousness, the reduction of aversiveness attributable to controllable shock may have been slight. A second reason why Schuster and Rachlin (1968) may not have found differences relates to their procedure. Responding produced shock, but failure to respond halted food reinforcement. The conflict involved may have reduced the desirability of having control. In support of this argument, Weiss (1971b) found that punishing the avoidance response resulted in increased ulceration among controllable-shock subjects relative to yoked controls.

For these reasons, the Schuster and Rachlin (1968) study is not definitive with respect to preference for controllable over uncontrollable shock. Would preference be found if the choice were between escapable and inescapable shock using highly aversive levels of 
shock? Experiments 1 and 2 addressed this question, the former while parametrically varying shock duration, the latter while holding shock duration constant. Would avoidable shock be preferred to unavoidable shock, and would this preference, if found, be altered by the presence or absence of signals predicting shock? These questions were addressed in Experiment 3.

\section{EXPERIMENT 1}

For the first experiment, subjects were given a choice between escapable and inescapable shock while relative shock duration varied parametrically.

\section{Subjects}

\section{Method}

Five naive female Sprague-Dawley rats (Holtzman Co.), 90-130 days old at the start of the experiment, served for $6 \mathrm{~h}$ every other day.

\begin{abstract}
Apparatus
The subjects were tested in two operant conditioning chambers enclosed in sound-attenuating boxes. Each operant chamber was constructed of sheet aluminum and measured $25.8 \mathrm{~cm}$ long $x$ $23.2 \mathrm{~cm}$ wide $\times 27.3 \mathrm{~cm}$ high. To discourage unauthorized avoidance of shock, a Plexiglas false ceiling was mounted $10.1 \mathrm{~cm}$ above the floor. A Plexiglas door served as the front wall. Mounted on the right wall $5.1 \mathrm{~cm}$ above the floor were two levers: a Lehigh Valley retractable lever on the left and a Gerbrands lever on the right. Both required a force of .19 N (20 g) to depress. A 1.2-cm white-jeweled cue light mounted $8.5 \mathrm{~cm}$ above the left lever terminated at the start of the experimental session. A 2.54-cm whitejeweled houselight mounted $15 \mathrm{~cm}$ above the left lever served as the correlated stimulus. Scrambled shock $(75 \mathrm{~mW})$ was generated by a constant wattage shock source (BRS Inc.) and was delivered to the subject through a grid floor of $.64-\mathrm{cm}$ stainless steel grid bars spaced $1.91 \mathrm{~cm}$ center-to-center, which ran parallel to the front of the chamber. Response levers and the metal walls acted as one contact of the grid-scrambling circuit. An electronic circuit measured and recorded escape latencies to the nearest millisecond.
\end{abstract}

\section{Procedure}

General procedure. All subjects received both an escapable and an inescapable shock condition. In the escapable shock condition, the correlated stimulus was on and the retractable lever was extended. When shock occurred, it could be terminated by a single response on the retractable lever. Shock terminated automatically after $10 \mathrm{sec}$ if the subject failed to respond on the lever. In the escapable condition, the correlated stimulus was off and the lever was retracted. Shock in this condition could not be terminated by the subject but remained on for a fixed duration, which was varied parametrically (see below). Shock was delivered on a VT 2-min schedule according to the Fleshler-Hoffman (1962) progression, modified to accept the minimum intershock interval of 5 sec.

The subjects were given experience with each of these conditions (training) and were then tested for preference (changeover). Across these training-testing sequences, the relative duration of shock in the two conditions was varied by changing the duration of shock in the inescapable condition. This procedure made shock duration and controllability orthogonal and eliminated the need for a yoked design. Yoked designs have been criticized as a possible source of bias in studies of controllability (Church, 1964; Black, Note 1).

Escape training. The subjects were pretrained under the escapable shock condition until mean escape latencies stabilized within $.1 \mathrm{sec}$ over three consecutive sessions. During pretraining, the changeover lever was covered.
Baseline training. In each baseline training session, $3 \mathrm{~h}$ of the inescapable condition were followed by $3 \mathrm{~h}$ of the escapable condition. To discourage superstitious escape responding, the changeover lever remained covered for the first three training sessions. The lever was then uncovered and remained available thereafter. During training, responding on the changeover lever had no programmed consequences, but the responses and the time that would have been spent in the changeover condition had these responses been effective were recorded. The latter measure provided the baseline for subsequent changeover testing. Subjects remained in training until mean escape latencies stabilized within $.1 \mathrm{sec}$ and percent changeover time stabilized within $10 \%$ over three consecutive sessions.

Changeover. Preference for the escapable condition was assessed by placing the subject in the inescapable condition. A single response on the changeover lever produced the escapable condition for $1 \mathrm{~min}$ (changeover period). Responses made on the changeover lever during the changeover period had no scheduled consequences. Following each changeover period, the inescapable condition was reinstated and remained in effect until the next changeover response. To minimize the effects of shock-elicited responding on changeover time, responses during and for $2.5 \mathrm{sec}$ after shock were ineffective in producing changeover.

Preference for the inescapable condition was assessed similarly, except that subjects began in the escapable condition and changed to the inescapable condition. Subjects remained in changeover until the percent time spent in the changeover condition stabilized within $10 \%$ across three successive sessions.

Parametric manipulation. The duration of inescapable shock was varied across the training-testing sequences. It began at .1 $\mathrm{sec}$ and increased in .1-sec steps to .5 sec (ascending series), then decreased in .1-sec steps to $.1 \mathrm{sec}$ (descending series). If the subject failed to respond above baseline on the changeover lever during testing, baseline training was repeated at the same duration of inescapable shock, and changeover to the opposite condition was tested. When preference for one of the conditions appeared, or when no preference for either condition was found, the duration of inescapable shock was changed to the next value in the series. Early in the experiment, testing in each direction was done twice, but this proved unfruitful and was reduced to once. Subject E-6 did not receive the $.5-\mathrm{sec}$ condition as changeover performance reached asymptote at $.4 \mathrm{sec}$.

\section{Choice}

\section{Results}

Figure 1 shows percent time spent in the escapable condition for each subject as a function of the difference in shock duration between escapable and in-

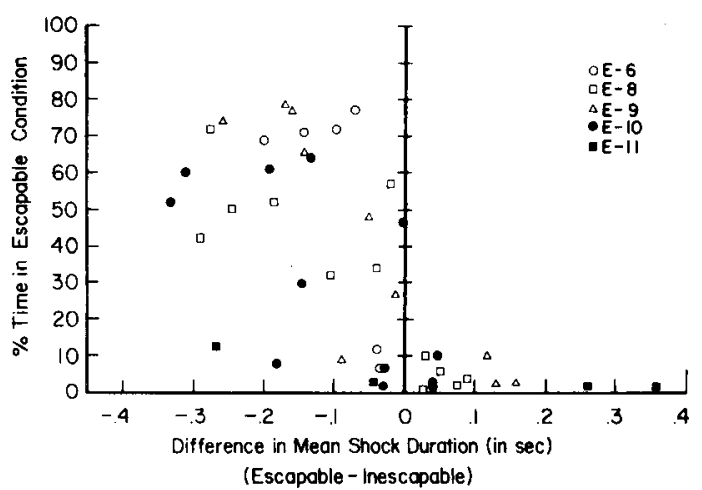

Figure 1. Percent time spent in the escapable shock condition as a function of relative shock duration (escapable-inescapable shock duration) in Experiment 1. Each point represents the mean of the last three sessions in each condition. 
escapable conditions. Each point represents the mean of the last 3 days at each inescapable shock duration. Because subjects controlled mean shock duration in the escapable condition, the difference in shock duration between conditions was also partly under subject control. Nevertheless, parametric variation of inescapable shock duration succeeded in producing a range of difference values, both negative (escapable shock shorter than inescapable shock) and positive (inescapable shock shorter than escapable shock). The percent time spent in the escapable condition varied as a function of this difference value. When escapable shock was shorter, subjects tended to change to the escapable condition, but they failed to change to the escapable condition when escapable shocks were longer. (Levels below $15 \%$ are essentially baseline amounts.) Subjects E-6 and E-9 showed this pattern most clearly. Subject E-6 responded strongly for the escapable condition until the mean difference in shock duration was less than $.1 \mathrm{sec}$, but differences closer to zero produced baseline performance levels. Subject E-9 also changed strongly to the escapable condition at differences greater than $.1 \mathrm{sec}$ but ceased responding when escapable shock duration exceeded that of inescapable shock. Subjects E-8 and E-10 exhibited similar functions but did not respond as strongly for the escapable condition at the higher negative values. Subject E-11 failed to change to the escapable condition at the two negative values obtained.

Figure 2 shows the percent time spent in the inescapable condition for each subject as a function of shock duration differences. Performance of subjects when changing to inescapable shock presents a mirror image of performance when changing to escapable shock (Figure 1). Subjects failed to change to the inescapable condition when shorter durations of shock could be obtained in the escapable condition (negative difference values), but tended to change



Figure 2. Percent time spent in the inescapable shock condition as a function of relative shock duration (escapable-inescapable shock duration) in Experiment 1. Each point represents the mean of the last three sessions in each condition. strongly to the inescapable condition when shorter shocks could be obtained there (positive value differences). An advantage of less than $.1 \mathrm{sec}$ in mean shock duration was often sufficient to produce strong preference for the inescapable condition (e.g., Subjects E-6 and E-9). The sensitivity of these subjects to relative shock duration is remarkable when one recalls that comparison was being made between fixed duration inescapable shocks and escapable shocks of varying durations. The scatter observed in the data points of some subjects may reflect the difficulty of this discrimination.

Taken together, the data of Figures 1 and 2 indicate a strong functional relation between preference and relative shock duration. Subjects tended to change over when doing so reduced shock duration. No subject changed over when doing so increased shock duration. In contrast, there is no evidence in these data that controllability is important. Had subjects preferred control, they should have tolerated increased shock duration to obtain the escapable condition (Figure 1). They did not. By the same logic, they should have tolerated higher shock durations and remained in the escapable condition (Figure 2); and again, they did not. Instead, they changed to the inescapable condition whenever that condition offered a discriminable reduction in shock duration. Thus, choice, while strongly controlled by relative shock duration, was unaffected by the presence or absence of control.

\section{EXPERIMENT 2}

Experiment 1 offered no support for the hypothesis that having control over shock lowers the aversiveness of a shock situation. However, the generality of this conclusion needs to be explored. Shock durations between conditions were rarely equal in Experiment 1 , nor were the variances equated; these differences may have affected choice. Furthermore, shock durations tended to be very short; this may have attenuated differences in the aversiveness of the two conditions.

Experiment 2 ruled out these possibilities by holding shock duration constant at $1.5 \mathrm{sec}$ in both conditions. This was accomplished in the following manner. In the escapable condition, responses during the first $1.5 \mathrm{sec}$ of shock caused termination to occur at $1.5 \mathrm{sec}$, irrespective of the actual response latency. Responses after $1.5 \mathrm{sec}$ terminated shock instantly. If the rat consistently responded during the first $1.5 \mathrm{sec}$ of shock, all shock in the escapable condition would be $1.5 \mathrm{sec}$ long. Since all shocks delivered in the inescapable condition, where the escape lever was withdrawn, were also $1.5 \mathrm{sec}$ long, such behavior would result in identical shock durations in the escapable and inescapable conditions. 
Method
Subjects
Three female Sprague-Dawley rats (Holtzman Co.), 90-130 days
old at the start of the experiment, served for $6 \mathrm{~h}$ every other day.

\section{Apparatus}

The apparatus was the same as that used in Experiment 1.

\section{Procedure}

Escape training. The changeover lever was covered, and the escape lever was extended into the chamber. When a shock occurred, a single response on the escape lever produced shock termination. If the subject failed to respond, shock terminated automatically after $10 \mathrm{sec}$ had elapsed. When the subjects were responding reliably, the minimum duration contingency was introduced. Under this contingency, a response occurring during the first $1.5 \mathrm{sec}$ of shock caused shock to terminate $1.5 \mathrm{sec}$ after onset. A response after $1.5 \mathrm{sec}$ produced immediate shock termination, while failure to respond yielded automatic termination at $10 \mathrm{sec}$. After 1-5 days in this condition, baseline training was begun.

Baseline training. The changeover lever was uncovered and remained available thereafter. During baseline training, responses on the changeover lever had no programmed consequences but the responses and the time that would have been spent in the changeover condition had these responses been effective were recorded. Each training session consisted of $3 \mathrm{~h}$ of escapable shock followed by $3 \mathrm{~h}$ of the inescapable shock. Under the escapable condition, the correlated stimulus was on, the escape lever was extended, and the minimum-duration escape contingency was in effect. During the inescapable condition, the correlated stimulus was off, the escape lever was retracted, and $1.5 \mathrm{sec}$ inescapable shock was delivered independently of responding. Histograms of response latencies during escape were constructed after each session. Changeover was initiated when response distributions stabilized and baseline changeover responding remained within $10 \%$ over three consecutive sessions.

Changeover. The changeover procedure was similar to that used in the first experiment, except that shock duration in the inescapable condition was not parametrically varied. Following training, Subjects E-31 and E-32 received the following conditions: changeover to inescapable shock, changeover to escapable shock, changeover to inescapable shock (replication), and changeover to escapable shock (replication). Subject E-30 received the same conditions in reverse order. Each condition remained in effect until percent time spent in changeover had stabilized within $10 \%$ over three consecutive sessions.

\section{Results}

The success of this experiment depended upon whether subjects would respond within the 1.5 -sec minimum duration period during shock in the escapable condition. If they did, then shock durations in the escapable and inescapable condition would be equal. Examination of latencies obtained in the final sessions of training showed that subjects almost invariably responded well within the time period of $1.5 \mathrm{sec}$. Thus, shock duration was virtually equated between the escapable and inescapable conditions prior to the changeover phase.

The choice data can be summarized briefly. When shock duration was held constant for escapable and inescapable conditions, preference did not develop for either condition.

Taken together, the first two experiments argue strongly that escapable and inescapable shock condi- tions having the same shock parameters are equally aversive.

\section{EXPERIMENT 3}

Finding no difference between the aversiveness of escapable or inescapable shock in this study and between response dependent or independent shock in the study by Schuster and Rachlin (1968) may reflect a general finding with respect to controllability. However, it may be argued that escape and punishment constitute rather restricted forms of control and, therefore, might not exert as much effect as would a more potent form. How one defines the "amount" of control is a difficult problem, but one approach might be to examine the degree to which a response reduces exposure to the aversive event. Under this definition, avoidance would qualify as a more potent response than escape, since it is only under the avoidance contingency that the subject could eliminate all contact with shock. Would subjects prefer controllable over uncontrollable shock if avoidance were the method of control? In Experiment 3, subjects were given the same number of shocks when shock was avoidable and when shock was unavoidable. Each condition was identified by a separate stimulus. After extensive training, the subjects were given a choice between the two conditions.

\section{Method}

\section{Subjects}

Twelve Sprague-Dawley (Holtzman Co.) female rats, 90-130 days old at the start of the experiment, served every other day in 6-h sessions. Eight others were dropped from the experiment for various reasons, as described below.

\section{Apparatus}

The apparatus was the same as that used in Experiments 1 and 2 . In addition, a magnetic tape system was added and used to record tones and shocks whenever they occurred during the avoidable shock condition. Tapes were played back during the unavoidable shock condition to reproduce the sequence of tones and shocks received under the previous avoidance condition.

\section{Procedure}

General procedure. The same general choice procedure used in Experiments 1 and 2 was again employed. Subjects received pretraining in free-operant (Sidman) avoidance, then training under avoidable and unavoidable shock conditions, and then were allowed to choose between the two schedules.

Avoidance training. The Sidman schedule in effect used the following values: SS interval, $8 \mathrm{sec}$; RS interval, $20 \mathrm{sec}$; shock, $.5 \mathrm{sec}, 75 \mathrm{~mW}$. In order to discourage avoidance due to shockelicited responding, responses on the avoidance lever during and for .5 sec after shock were made ineffective. Half of the subjects received signaled avoidance, half unsignaled. In the signaled condition, all shocks were preceded by a 5-sec tone. Pretraining was continued until the percent shocks avoided stabilized at or above $55 \%$. Three subjects in the signaled condition and three in the unsignaled failed to meet the latter criterion and were replaced.

Training. Training consisted of alternating sessions of avoidable and unavoidable shock. During the latter, the houselight was off and the avoidance lever was retracted. Tones and shocks delivered 
during the avoidance condition were recorded on magnetic tape and "played back" during the subsequent unavoidable condition, thus insuring identical patterns of these stimuli under both conditions. Responses on the changeover lever had no scheduled consequences, but responses and time that would have been spent in changeover were recorded.

Changeover. The changeover contingency was the same as in previous experiments. The RS and SS timers stopped but did not reset during presentations of the unavoidable shock condition. Subjects were first trained and tested with the RS interval set at $20 \mathrm{sec}$ (Phase I). Following replication, the RS interval was changed to $60 \mathrm{sec}$ and the experiment repeated (Phase II).

Changeover to signaled shock (Phase III). Signaled-shock animals continued to receive signaled shock in the avoidable condition; but in the unavoidable condition, the signals were deleted. Following training, these subjects were given the opportunity to change to signaled avoidable shock. Animals in the unsignaled shock group continued to receive unsignaled shock in the avoidable condition, but shock was now signaled in the unavoidable condition. Following training, these subjects were given the opportunity to change to signaled unavoidable shock.

\section{Results and Discussion \\ Avoidable vs. Unavoidable-Phases I and II \\ During training, subjects generally avoided about $80 \%$ of the shocks; the one exception was Sub- ject SA-8, which avoided about $60 \%$ of the shocks.}

For those subjects receiving only signaled shock, baseline responses on the changeover lever were consistently low. For those subjects receiving only unsignaled shock, baseline responses were consistently higher. Figures 3 and 4 present changeover data for subjects receiving signaled and unsignaled shock, respectively. When given the opportunity to change from avoidable to unavoidable shock, none of the 12 subjects did so consistently. One subject did increase responding under the changeover condition, but this subject also had a sizable increase in baseline responding. When given the opportunity to change from unavoidable to avoidable shock, again, none of the subjects did so consistently. It is clear from these data that when shock frequency is constant under avoidable and unavoidable conditions, having or lacking control over shock is unimportant. When the responseshock interval was reset to $60 \mathrm{sec}$ and the experiment repeated, the results were similar to those obtained with a response-shock interval of $20 \mathrm{sec}$.

\section{Changeover to Signaled Shock}

Failure of subjects to change either to avoidable or to unavoidable shock suggests that being able to

\section{SIGNALED SHOCK SUBJECTS}



Figure 3. Percent time spent in the avoidable or unavoidable shock conditions by signaled shock subjects in Experiment 3. Each point represents the mean of the last three sessions in each condition. In Phases I and II, all shocks were signaled and the RS interval was 20 and $60 \mathrm{sec}$, respectively. In Phase III, signals were removed from the avoidable shock schedule. 


\section{UNSIGNALED SHOCK SUBJECTS}



\section{SESSIONS}

Figure 4. Percent time spent in the avoidable or unavoidable shock condition by unsignaled shock subjects in Experiment 3. Each point represents the mean of the last three sessions in each condition. In Phases $I$ and II, all shocks were unsignaled and the RS interval was 20 and $60 \mathrm{sec}$, respectively. In Phase III, signals were added to the unavoidable shock schedule.

avoid shock is unimportant in choice. This conclusion would be strengthened if it could be shown that subjects will develop a preference under other slightly different conditions. Since preference for signaled shock is well established (e.g., Badia \& Culbertson, 1972; Badia et al., 1976), conditions were modified to give these subjects the option of changing from unsignaled to signaled shock. This was accomplished for signaled-shock subjects by removing the signals from the unavoidable shock condition and for the unsignaled-shock subjects by signaling shocks in the unavoidable shock condition. Under these conditions, the former group should have changed to avoidable shock and the latter group to unavoidable shock. Actual performance conformed closely to this expectation (see Figures 3 and 4). Three of the five remaining subjects previously given only signaled shocks preferred the signaled avoidable shock condition. Failure of two subjects to change over (SA-7 and SA-9) may relate to their extremely low baselines. Four of the six subjects previously given only unsignaled shocks preferred the signaled unavoidable condition.

\section{GENERAL DISCUSSION}

When given the choice between controllable and uncontrollable shock, subjects find the two conditions equally aversive whether the contingency between response and shock is one of escape (Experiments 1 and 2), one of avoidance (Experiment 3), or one of punishment (Schuster \& Rachlin, 1968). While this finding is perhaps not surprising when viewed in the context of the negative law of effect (Rachlin \& Herrnstein, 1969), it is surprising when compared with data indicating that lack of control over an aversive event often results in profound behavioral and physiological effects (Seligman, 1975). How can these disparate findings be reconciled? Several alternative views are possible, given different assumptions. First, one can assume that controllability simply has no independent effects on the aversiveness of a situation. This is essentially the position adopted by Baum (1973) when he concluded that "the value of a situation depends simply on rate of punishment and rate of reinforcement, regardless of whether the punishment and reinforcement arise 
from behavior." If control has no effects, then the observed physiological and behavioral effects must be artifacts. Given the number of experiments finding effects of controllability, is this conclusion plausible? Perhaps. Differences in rate of ulceration and other physiological measures could reflect differences in predictability. Whenever control over shock is introduced, increased predictability results, since responses themselves become reliable predictors of shock and shock-free periods. However, if this is so, then a dilemma is posed. It could be argued that our results, which show no effect for controllability, therefore, must also show no effect for predictability. The latter, of course, is contrary to much of the literature. This dilemma can be resolved by assuming that shock termination, i.e., safety, was equally predictable under both controllable and uncontrollable conditions because of the briefness of the shocks. Essentially, subjects could predict shock termination whether or not shock was controllable.

The disparate findings may also result from the type of experimental design that is used. In the present study, subjects experienced both controllable and uncontrollable conditions, i.e., within-subjects design. Other studies that showed control over an aversive event to have behavioral and physiological effects were between-subjects designs. The latter type of design precluded subjects from contrasting the various conditions. Others have shown that different designs lead to different outcomes (Grice, 1966). It may be that allowing comparisons between both conditions teaches the animal in a rather direct way that having control over shock does not result in any change in shock parameters relative to the uncontrollable situation. [A growing literature of the phenomenon called "learned helplessness" documents a similar effect: experience with controllable shock seems to eliminate the interfering effects of prior exposure to uncontrollable shock on subsequent avoidance responding (e.g., Seligman, 1975).]

The conflicting findings may also relate to the preference paradigm itself. Choice between conditions is itself a form of control and, thus, may eliminate the basis for choice. For example, in Experiment 1 , subjects could control shock duration by responding in the escapable condition or by choosing the inescapable condition. Perhaps we have simply offered the subject alternative forms of control over shock duration, one of which we have labeled the "choice" response. But if control is reinforcing in and of itself, wouldn't the subject attempt to maximize his exposure to it? To do so would require staying in the escapable condition. By responding for the inescapable condition, it is true, the subject would be indirectly controlling the duration of shock. Yet, at the same time, the subject would be giving up all further opportunity to control shock. Based upon this, it seems unlikely that the control inherent in the choice procedure would override preference for control in the current study. We should note, however, that control may have been preferred if other parameters had been used in our study. Possibly control is preferred only when some quality of the aversive event is uncertain, e.g., longer, more variable shock durations.

Our preceding comments deal exclusively with aversive events. Controllability is apparently less an issue in the current literature dealing with appetitive events, e.g., the "contrafreeloading" phenomenon (Osborne, 1977). Osborne's review indicates that under certain conditions, rats and pigeons will respond for food in the presence of free food.

The present research asked the question, "Do subjects prefer controllable over uncontrollable shock?" The answer was "No." Our preference findings agree with those of Schuster and Rachlin (1968) but conflict with other behavioral and physiological findings. We have offered several possible reasons why the conflicting findings occurred, none of them very satisfying. The data necessary to resolve the conflicting findings are not yet available.

\section{REFERENCE NOTE}

1. Black, A. H. A comment on yoked control designs (Tech. Rep. 11). Hamilton, Ont: McMaster University, Department of Psychology, 1967.

\section{REFERENCES}

Badia, P., \& Culbertson, S. The relative aversiveness of signalled vs. unsignalled escapable and inescapable shock. Journal of the Experimental Analysis of Behavior, 1972, 17, 463-471.

Badia, P., Culbertson, S., \& Lewis, P. The relative aversiveness of signalled vs. unsignalled avoidance. Journal of the Experimental A nalysis of Behavior, 1971, 16, 113-121.

Badia, P., Harsh, J., Coker, C. C., \& Abbott, B. Choice and the dependability of stimuli that predict shock and safety. Journal of the Experimental Analysis of Behavior, 1976, 26, 95-111.

BAUM, W. M. The correlation-based law of effect. Journal of the Experimental A nalysis of Behavior, 1973, 20, 137-153.

Church, R. M. Systematic effect of random error in the yoked control design. Psychological Bulletin, 1964, 62, 122-131.

Desiderato, O., \& Newman, A. Conditioned suppression produced in rats by tones paired with escapable or inescapable shock. Journal of Comparative and Physiological Psychology, $1971,77,427-431$.

Fisher, C., \& Badia, P. Preference for signalled or unsignalled shock in goldfish. Bulletin of the Psychonomic Society, 1975, 6, 195-197.

Fleshler, M., \& Hoffman, H. S. A progression for generating variable-interval schedules. Journal of the Experimental Analysis of Behavior, 1962, 5, 529-530.

Grice, R. G. Dependence on empirical laws upon the source of experimental variation. Psychological Bulletin, 1966, 66, 488-498.

ImADA, H., \& SogA, M. The cer and bel as a function of predictability and escapability of an electric shock. Japanese Psychological Research, 1971, 13, 115-122. 
Moot, S. A., Cebula, R. P., \& Crabtree, J. M. Instrumental control and ulceration in rats. Journal of Comparative and Physiological Psychology, 1970, 71, 405-410.

Mowren, O. H., \& VIEK, P. An experimental analogue of fear from a sense of helplessness. Journal of Abnormal and Social Psychology, 1948, 43, 193-200.

Osbonne, F. H., Mattingly, B. A., Redmon, W. K., \& OsBorne, J. S. Factors affecting the measurement of classically conditioned fear in rats following exposure to escapable vs. inescapable shock. Journal of Experimental Psychology: Animal Behavior Processes, 1975, 1, 364-373.

OsBonNe, S. R. The free food (contrafreeloading) phenomenon: A review and analysis. Animal Learning \& Behavior, 1977, 5, 221-235.

Rachlin, H., \& Herrnstein, R. J. Hedonism revisited: On the negative law of effect. In B. A. Campbell \& R. M. Church (Eds.), Punishment and aversive behavior. New York: AppletonCentury-Crofts, 1969.

Schuster, R., \& Rachlin, H. Indifference between punishment and free shock: Evidence for the negative law of effect. Journal of the Experimental Analysis of Behavior, 1968, 11, 777-786.

Seligman, M. E. P. Helplessness. San Francisco: Freeman, 1975.

WEISS, J. M. Effects of coping responses on stress. Journal of Comparative and Physiological Psychology, 1968, 65, 251-260.
WEISs, J. M. Effects of coping behavior in different warning signal conditions on stress pathology in rats. Journal of Comparative and Physiological Psychology, 1971, 77, 1-13. (a)

WEISs, J. M. Effects of punishing the coping response (conflict) on stress pathology in rats. Journal of Comparative and Physiological Psychology, 1971, 77, 14-21. (b)

WEISS, J. M. Effects of coping behavior with and without feedback signal on stress pathology in rats. Journal of Comparative and Physiological Psychology, 1971, 77, 22-30. (c)

Weiss, J. M., Stone, E. A., \& Harrell, N. Coping behavior and brain norepinephrine level in rats. Journal of Comparative and Physiological Psychology, 1970, 72, 153-160.

\section{NOTE}

1. Schuster and Rachlin's (1968) study was not designed to address the controllability question but to assess the negative law of effect. Apparent shortcomings, when viewed in the present context, may not apply when viewed in terms of the study's original purpose.

(Received for publication February 28, 1978; revision accepted September 25, 1978.) 